\title{
Effect of Musician's Earplugis on Sound Level and Spectrum During Musical Performances
}

\author{
Emil Kozłowski \\ Central Institute for Labour Protection - National Research Institute (CIOP-PIB), Poland
}

\begin{abstract}
Jan Żera
Central Institute for Labour Protection - National Research Institute (CIOP-PIB), Poland Institute of Radioelectronics, Faculty of Electronics and Information Technology, Warsaw University of Technology, Warszawa, Poland

The Fryderyk Chopin University of Music, Warszawa, Poland
\end{abstract}

\section{Rafal Mhyński}

Central Institute for Labour Protection - National Research Institute (CIOP-PIB), Poland

In this study, change in A-weighted and 1/3-octave sound pressure levels (SPLS) was used to assess the influence of wearing earplugs by musicians on their musical performances. Seven soloists and 3 music assembles performed 4 pieces of music with musician's earplugs donned and doffed. They used silicon custom moulded earplugs with acoustic filters designed to attenuate sound by 9, 15 or $25 \mathrm{~dB}$. Results showed that the use of earplugs affected the sound level and the spectrum of played sounds. This effect was the greatest for brass players. The difference between SPLs in high-frequency 1/3-octave bands and A-weighted SPLs with and without earplugs exceeded 5 and $15 \mathrm{~dB}$, respectively. Similar changes for woodwind, percussion and string instruments were less noticeable than for brass instruments; they were more than $5 \mathrm{~dB}$ for 1/3-octave spectra and no more than $2 d B$ for A-weighted SPL.

earplugs hearing protection noise sound pressure level musicians

\section{INTRODUCTION}

Various studies have shown that the sound of instruments affects musicians' hearing causing tinnitus, hyperacusis or even hearing loss [1, $2,3]$. Musicians are often exposed to as high a level of sound as the level of noise in industrial sectors. For example, the $A$-weighted equivalent continuous sound pressure level $L_{\text {Aeq }}$ measured over the duration of a single music piece, on the stage among musicians of a concert orchestra (wind instruments) is $83.0-106.5 \mathrm{~dB}$ [4]. Avoiding risk of hearing loss is especially important to musicians for whom good hearing is essential in their work.

Earplugs are a possible means to reduce the harmful influence of a high level of sound on hearing. The aim of this work was to study musicians' use of musician's earplugs during their performances to protect their hearing. The effect of the use of earplugs on solo and ensemble music performances was investigated with spectral

\footnotetext{
This paper has been prepared on the basis of the results of a research task carried out within the scope of the first stage of the National Programme "Improvement of safety and working conditions" partly supported in 2008-2010 — within the scope of state services — by the Ministry of Labour and Social Policy. The Central Institute for Labour Protection - National Research Institute is the Programme's main co-ordinator.

Correspondence and requests for offprints should be sent to Emil Kozłowski, CIOP-PIB, ul. Czerniakowska 16, 00-701 Warszawa, Poland. E-mail: <emkoz@ ciop.pl>.
} 
analysis of the sound played when the musicians played music with and without earplugs.

\section{METHODOLOGY}

In the first part of the study, measurements were conducted during seven solo performances by a flutist, a clarinetist, a trumpeter, a saxophonist, a violinist, a drummer and a vocalist. In the second part of the study, three music ensembles participated in measurements: a brass trio (a trumpet, a trombone and a French horn), a saxophone quartet (soprano, alto, tenor and baritone saxophones) and a woodwind quintet (a flute, an oboe, a clarinet, a bassoon and a French horn). Four pieces of music were performed in each performance. Musicians played with no hearing protectors (the reference condition) or used silicon custom moulded musician's earplugs with acoustic filters providing flat attenuation of 9,15 or $25 \mathrm{~dB}$.

Musicians performed pieces of music in a recording studio. The signal was captured with a Brüel\&Kjaer (Denmark) 4190 microphone, passed through a Brüel\&Kjaer 2669 preamplifier and analyzed with a Brüel\&Kjaer PULSE measurement system, controlled from a remote computer. The microphone was located $1.5 \mathrm{~m}$ from the players and $2 \mathrm{~m}$ above the floor.

\section{RESULTS}

The influence of wearing earplugs on musicians' performance was examined by comparing $1 / 3$-octave band spectrum and the $A$-weighted sound pressure level (SPL) of the music they played. Measurements were made for five conditions of four musical pieces: musicians performed without earplugs in the initial reference condition $a$, musicians played using musician's earplugs with the nominal attenuation of $9 \mathrm{~dB}$ (condition $b$ ), $15 \mathrm{~dB}$ (condition $c$ ) and $25 \mathrm{~dB}$ (condition $d$ ). Finally, music was performed without earplugs again as a final reference condition $e$. Using initial $a$ and final $e$ reference conditions made it possible to control changes in performance due to the length of the recording session, which lasted $\sim 40 \mathrm{~min}$, and the effect of previous exposure to sound attenuated with earplugs.

Analysis of the sound spectrum in 1/3-octave bands between performance without hearing protection and performances with the use of 9-, 15- and 25-dB earplugs showed changes specific for different groups of instruments. Figure 1 shows examples of those changes for the trumpet and the clarinet representing brass and woodwind instruments, respectively.

There was a great change in $1 / 3$-octave SPLs for the trumpet (Figure 1, left column). The level systematically fell by $5-15 \mathrm{~dB}$ in the highfrequency range above $2 \mathrm{kHz}$. These drops depended on the attenuation of the earplugs. In contrast, wearing earplugs did not affect very much clarinet players (the right panels of Figure 1). The level of the 1/3-octave band fell less than $4 \mathrm{~dB}$. The results did not show great differences among performances with 9-, 15- and 25-dB earplugs, and did not depend on the frequency as in the case of the trumpet. In addition, these differences were not greater than the ones between the initial $a$ and final $e$ reference conditions.

Figure 2 illustrates the results of measurements of two pieces of music. The change in levels in 1/3-octave bands for the brass trio when the musicians used earplugs was $10-20 \mathrm{~dB}$ in the frequency range above $2 \mathrm{kHz}$. These results were very similar to those for the trumpet (Figure 1). Data in the right column of Figure 2 illustrate measurements during the woodwind quintet's performance: the results clearly corresponded with those for the clarinet (Figure 1). Using earplugs did not affect the spectrum of music very much.

The change in sound spectra in Figures 1-2 are only examples of an either great or small influence of wearing earplugs on music. Similarly great changes to those of the brass quintet were recorded for the saxophone quartet, for which changes in $1 / 3$-octave spectra (lower levels) reached $8 \mathrm{~dB}$ in the frequency range above $1 \mathrm{kHz}$. It was thus clear that saxophones (to a larger extent than other woodwind instruments) were controlled by players. 

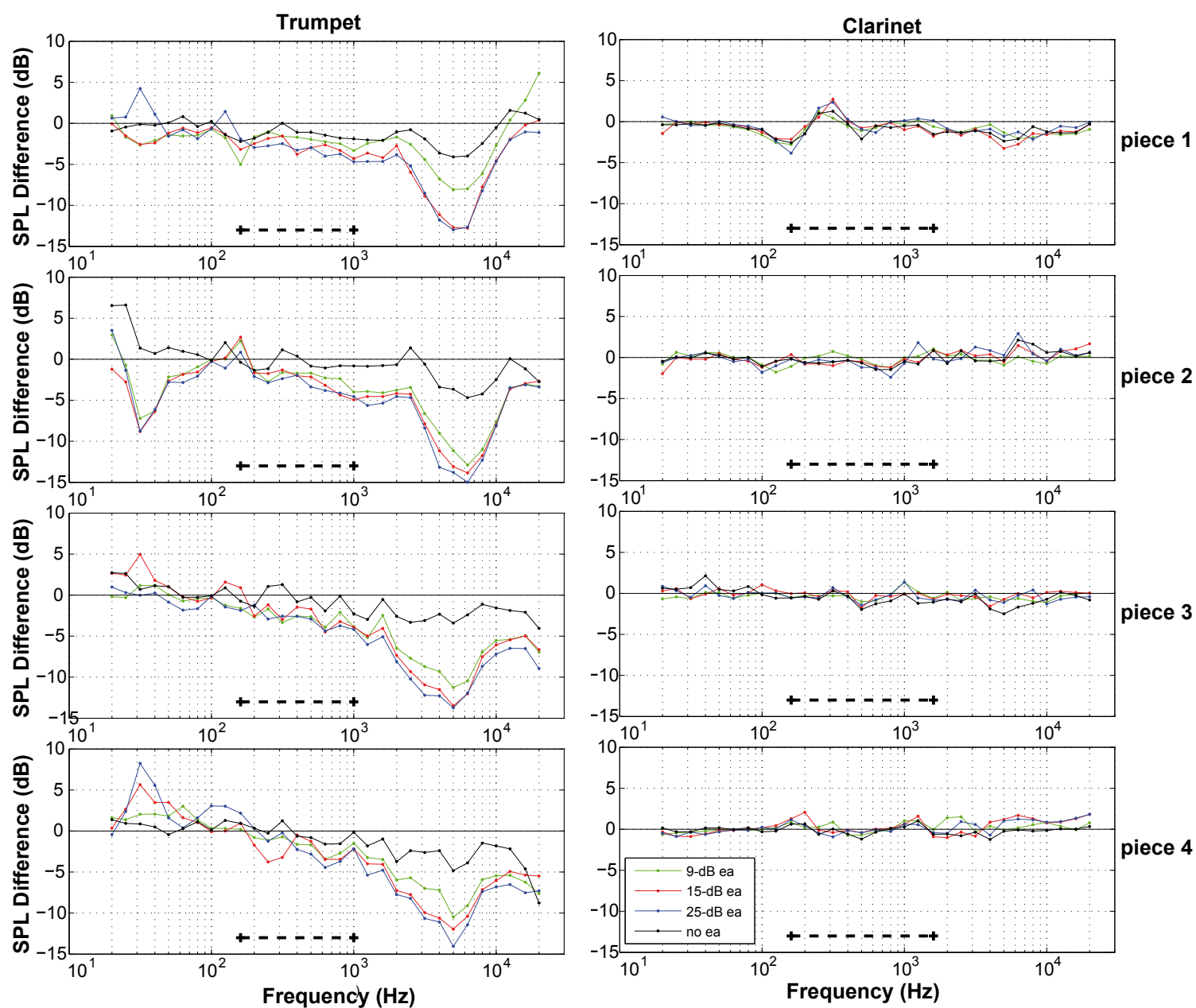

Figure 1. Difference in sound pressure level (SPL) between performance with earplugs of 9-dB (green), 15-dB (red) and 25-dB (blue) nominal attenuation (conditions $b, c, d$ ) and without earplugs (condition $a$ ). The black line represents the difference between the final (condition $e$ ) and initial (condition a) performances without earplugs. The dashed line at the bottom of each graph represents the instrument's musical scale. Data for the trumpet and the clarinet. Notes. ea-earplugs.

Moreover saxophones and brass instruments were controlled in similar way; feedback consisting in listening to emitted sounds was crucial.

Earplugs also had a significant influence on solo saxophonists. Average sound spectra of the music they played showed levels in 1/3-octave bands decreased by $~ 5-10 \mathrm{~dB}$ above $1 \mathrm{kHz}$ when musicians used 9-, 15- and 25-dB earplugs. Using earplugs had little influence on both players of woodwind instruments, which included the flute (the level changed less than $3 \mathrm{~dB}$ ) and the piccolo (the level changed less than $4 \mathrm{~dB}$ ), and the vocalist (the level changed less than $5 \mathrm{~dB}$ ). The influence of earplugs was thus as low as for the clarinet (Figure 1). Playing the violin, the xylophone and the snare drum also revealed that using earplugs had little influence on the spectrum of produced sound. For all these instruments, musicians can probably use both feedback by listening to the sound and some motoric-mechanical feedback to control their performance. Any non-auditory control of playing helps in reducing the negative influence of earplugs when playing. Vocalists, for example, usually hear their own voice through bone conduction, which also diminishes the negative effect of earplugs.

The $A$-weighted sound levels were determined, as they correlated with changes in the level 

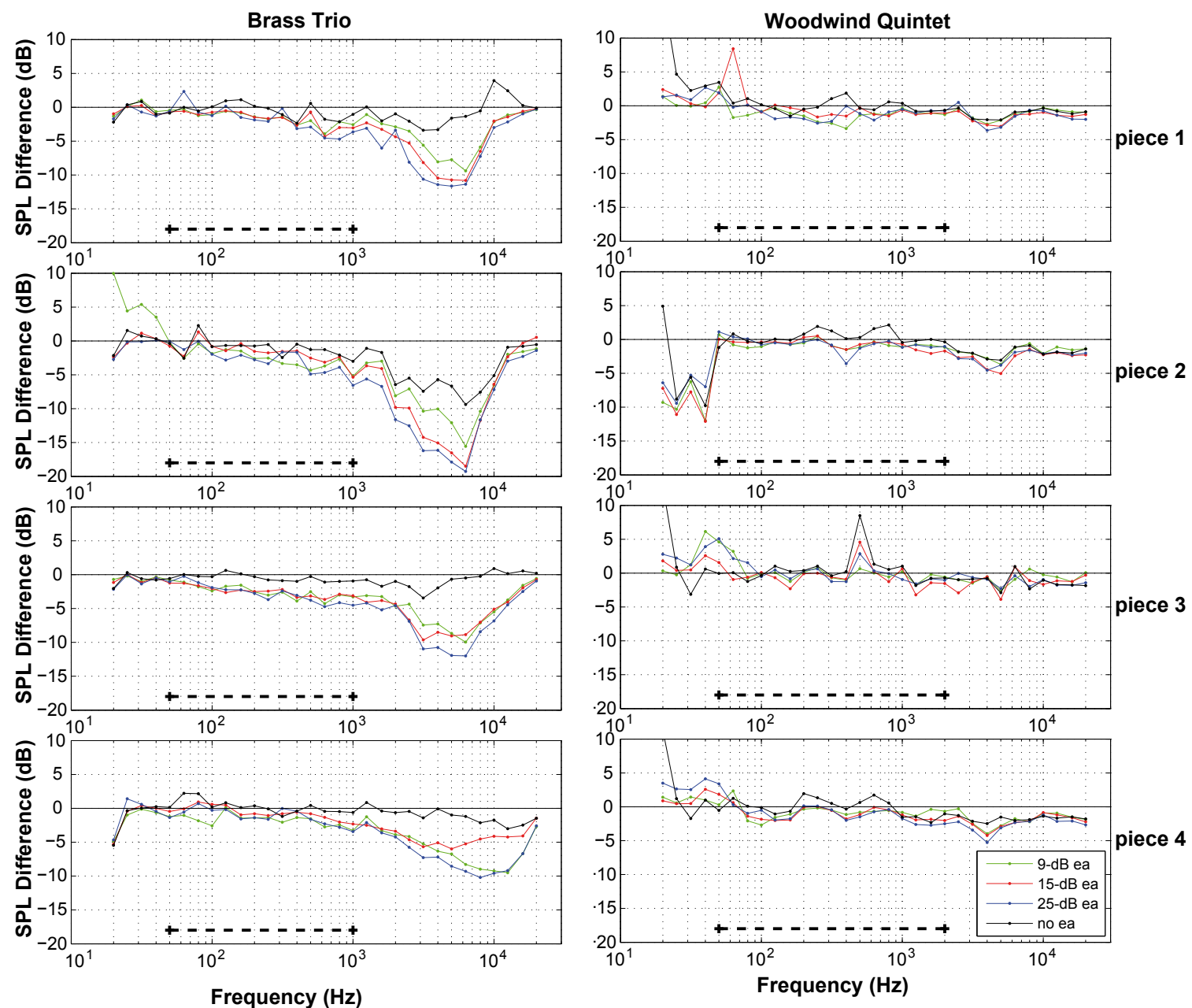

Figure 2. Difference in sound pressure level (SPL) between performances with earplugs of 9-dB (green), 15-dB (red) and 25-dB (blue) nominal attenuation (conditions $b, c, d$ ) and without earplugs (condition a). The black line represents the difference between the final (condition $e$ ) and initial (condition a) performances without earplugs. The dashed line at the bottom of each graph represents the instrument's musical scale. Data for the brass trio and the woodwind quintet. Notes. ea-earplugs.

of sound among various performances when musicians either donned or doffed earplugs. Figure 3 shows examples of $A$-weighted sound levels measured for the trumpet, the clarinet, the brass trio and the woodwind quintet. The highest differences in $A$-weighted sound levels between performances with earplugs donned and doffed were observed for the trumpet (Figure 3, upper left panel). The level of music played on the trumpet with $25-\mathrm{dB}$ earplugs decreased by almost $5 \mathrm{~dB}$. These data also show a regular decrease in level for earplugs with increasing attenuation. Similar results were obtained for the brass trio (Figure 3, lower left panel). In addition, all these data showed that the $A$-weighted levels of the second performance without earplugs (condition $e$ ) were lower than levels in initial reference condition $a$ without earplugs. This shows the importance of context. Having listened to sound attenuated with earplugs, musicians performed differently than usual without earplugs.

For woodwind instruments other than saxophones, the influence of wearing earplugs was smaller than that for brass instruments. Values of $A$-weighted sound levels when the clarinetist donned earplugs changed marginally only (Figure 3, upper right panel). A slightly greater effect of wearing earplugs was observed for the piccolo, the flute and the woodwind 

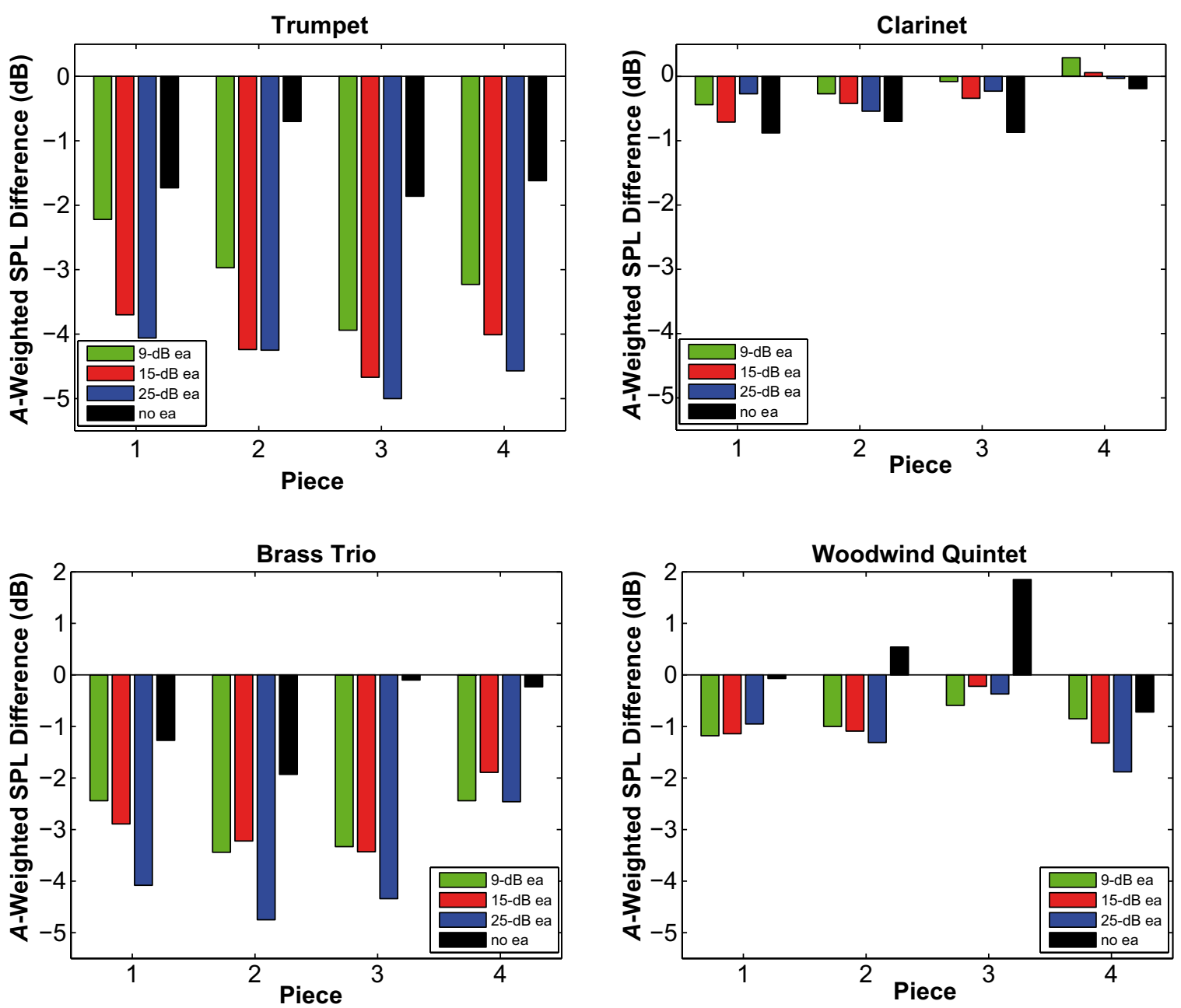

Figure 3. Difference in A-weighted pressure level (SPL) between performances with earplugs of 9-dB (green), 15-dB (red) and 25-dB (blue) nominal attenuation (conditions $b, c, d$ ) and without earplugs (condition a). The black bar represents the difference between the final (condition $e$ ) and initial (condition a) performances without earplugs. Data for the trumpet, the clarinet, the brass trio and the woodwind quintet. Notes. ea-earplugs.

quintet (Figure 3, lower right panel). The differences approached $2 \mathrm{~dB}$ and mainly depended on the piece that was played.

\section{CONCLUSIONS}

The results of this study showed that the use of earplugs had a pronounced effect on the sound level and the spectra of music. The effect of wearing earplugs was the greatest for brass instruments, with changes in 1/3-octave-band levels exceeding $15 \mathrm{~dB}$ in the high frequency range. Changes in $A$-weighted levels for those instruments were close to $5 \mathrm{~dB}$. Brass instruments require players to control loudness and timbre by listening to the sound they produce. Woodwind instruments due to strong coupling with the instrument pipe offer better control of the sound despite the limited ability to hear the sound. In general, earplugs has little effect on musicians' performance on all instruments that offer means to control sound other than just by listening to it (i.e., mechanomotorical control of sound). This does not mean, however, that the artistic quality of the performance remains unchanged. 


\section{REFERENCES}

1. Axelsson A, Lindner F. Hearing in classical musicians. Acta Otlaryngologica Suppl. 1981;377:3-74.

2. Rabinowitz J, Hausler R, Bristow G, Rey P. A study of the effect of loud music on musicians of the Orchestra de la Suisse Romande. Med Hyg (Geneve). 1982;40:1909-21.
3. Woolford DH, Carterette EC, Morgan DE. Hearing impairment among orchestral musicians. Music Percept. 1988;5:261-84.

4. Kozłowski E, Żera J, Młynski R. Sound exposure levels experienced by classical and rock musicians. In: Proceedings of 56 Otwarte Seminarium z Akustyki. 2009. p. 341-6. 